\title{
Caffeic Acid Phenethyl Ester: Consequences of Its Hydrophobicity in the Oxidative Functions and Cytokine Release by Leukocytes
}

\author{
Luana Chiquetto Paracatu, ${ }^{1}$ Carolina Maria Quinello Gomes Faria, ${ }^{1}$ \\ Camila Quinello, ${ }^{2}$ Camila Rennó, ${ }^{2}$ Patricia Palmeira, ${ }^{2}$ Maria Luiza Zeraik, ${ }^{3}$ \\ Luiz Marcos da Fonseca, ${ }^{1}$ and Valdecir Farias Ximenes ${ }^{1,4}$ \\ ${ }^{1}$ Department of Clinical Analysis, School of Pharmaceutical Sciences, São Paulo State University (UNESP), \\ 14801-902 Araraquara, SP, Brazil \\ ${ }^{2}$ Department of Pediatrics, Medical School, University of São Paulo, 05403-900 São Paulo, SP, Brazil \\ ${ }^{3}$ Department of Organic Chemistry, Institute of Chemistry, São Paulo State University (UNESP), 14800-900 Araraquara, SP, Brazil \\ ${ }^{4}$ Department of Chemistry, Faculty of Sciences, São Paulo State University (UNESP), 17033-360 Bauru, SP, Brazil
}

Correspondence should be addressed to Valdecir Farias Ximenes; vfximenes@fc.unesp.br

Received 22 April 2014; Revised 23 July 2014; Accepted 24 July 2014; Published 28 August 2014

Academic Editor: Raffaele Capasso

Copyright (c) 2014 Luana Chiquetto Paracatu et al. This is an open access article distributed under the Creative Commons Attribution License, which permits unrestricted use, distribution, and reproduction in any medium, provided the original work is properly cited.

\begin{abstract}
Numerous anti-inflammatory properties have been attributed to caffeic acid phenethyl ester (CAPE), an active component of propolis. NADPH oxidases are multienzymatic complexes involved in many inflammatory diseases. Here, we studied the importance of the CAPE hydrophobicity on cell-free antioxidant capacity, inhibition of the NADPH oxidase and hypochlorous acid production, and release of TNF- $\alpha$ and IL-10 by activated leukocytes. The comparison was made with the related, but less hydrophobic, caffeic and chlorogenic acids. Cell-free studies such as superoxide anion scavenging assay, triene degradation, and anodic peak potential $\left(E_{\mathrm{pa}}\right)$ measurements showed that the alterations in the hydrophobicity did not provoke significant changes in the oxidation potential and antiradical potency of the tested compounds. However, only CAPE was able to inhibit the production of superoxide anion by activated leukocytes. The inhibition of the NADPH oxidase resulted in the blockage of production of hypochlorous acid. Similarly, CAPE was the more effective inhibitor of the release of TNF- $\alpha$ and IL-10 by Staphylococcus aureus stimulated cells. In conclusion, the presence of the catechol moiety and the higher hydrophobicity were essential for the biological effects. Considering the involvement of NADPH oxidases in the genesis and progression of inflammatory diseases, CAPE should be considered as a promising anti-inflammatory drug.
\end{abstract}

\section{Introduction}

Propolis is a resin produced by honeybees and its chemical composition, colour, and aroma are changed according to geographical zones. Despite the chemical composition diversity, phenolic compounds are constituents that are always present in this natural product [1]. Among them, caffeic acid phenethyl ester is one of the propolis active components for which many potentially beneficial health properties have been demonstrated. Some recent findings include its antithrombotic potential through the inhibition of tumour necrosis factor- (TNF-) $\alpha$ induced endothelial tissue factor expression and activity [2]. Suppression of the phosphoinositide 3kinase/AKT/XIAP pathway has also been shown to lead to apoptosis in melanoma tumour cells both in vitro and in vivo [3]. Application is used for the treatment of burn wound healing, leading to a decrease in inflammatory parameters and in oxidative damage [4] and also has anti-Helicobacter pylori activity, through the inhibition of the Helicobacter pylori peptide deformylase [5].

NADPH oxidases are multienzymatic complexes which catalyse the one-electron reduction of molecular oxygen 
to superoxide anion radical $\left(\mathrm{O}_{2}{ }^{--}\right)$and are expressed in a variety of cell types. This multicomponent enzyme system is composed of two transmembrane proteins, p22phox and gp91phox, three cytosolic proteins, p47phox, p67phox, and p40phox, and a small G-protein, Rac [6]. The activation of NADPH oxidase involves the migration of the cytosolic proteins to the membrane, assembly of the enzyme complex, and the release of $\mathrm{O}_{2}{ }^{--}$into the intraphagosomal or extracellular space [7]. From $\mathrm{O}_{2}{ }^{--}$, a cascade of enzymatic reactions takes place, leading to the production of hydrogen peroxide $\left(\mathrm{H}_{2} \mathrm{O}_{2}\right)$, hydroxyl radical $\left({ }^{\circ} \mathrm{OH}\right)$, and hypochlorous acid (HOCl) [7].

Besides its essential role in the innate immune defence, there is increasing evidence of the involvement of NADPH oxidases in the genesis and progression of vascular, inflammatory, and degenerative diseases [8-12]. Hence, inhibitors of NADPH oxidases represent an alternative and promising therapeutic pathway for the treatment of these chronic inflammatory diseases [13]. Several phytochemicals have been proposed as potential inhibitors of NADPH oxidase, for instance quercetin [14], resveratrol [15], flavonoids [16], and apocynin [17]. In this scenario, we have recently demonstrated that the esterification of protocatechuic acid, a natural phenolic compound found in many edible and medicinal plants, significantly increased its efficacy as an inhibitor of the release of oxidants by stimulated neutrophils [18]. Compared to apocynin, which is the most employed inhibitor of NADPH oxidase, the heptyl ester of protocatechuic acid was about ten-fold more potent [18].

In light of these findings, here, we aim to study and compare caffeic acid and the related compounds, chlorogenic acid, caffeic acid phenethyl ester, and phenethyl cinnamate as potential inhibitors of NADPH oxidase enzymatic activity and cytokine production by leukocytes. The results confirmed our hypothesis, since a direct relationship was found between the hydrophobicity of the tested compounds and the cellular functions evaluated.

\section{Materials and Methods}

2.1. Chemicals. Caffeic acid phenethyl ester, caffeic acid, chlorogenic acid, phenethyl cinnamate, apocynin, 2,2' -azobis(2amidinopropane) hydrochloride (AAPH), 2,4,6-Tri(2-pyridyl)-S-triazine (TPTZ), dimethyl sulphoxide (DMSO), Brij 35, tung oil, 5-fluortryptamine, 2,2-diphenyl-1-picryl-

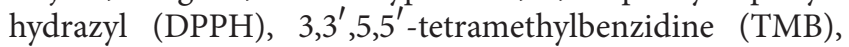
lucigenin, phorbol 12-myristate 13-acetate (PMA), taurine, Histopaque-1077, and Histopaque-1119 were purchased from Sigma-Aldrich Chemical Co. (St. Louis, MO, USA). 2-(4iodophenyl)-3-(4-nitrophenyl)-5-(2,4-disulfophenyl)-2H-tetrazolium monosodium salt (WST-1) was purchased from Santa Cruz Biotechnology (Santa Cruz, CA, USA). Amplex Red (10-acetyl-3,7-dihydroxyphenoxazine) was purchased from Invitrogen (Eugene, OR, USA). Myeloperoxidase (MPO) (EC 1.11.1.7) was purchased from Planta Natural Products (Vienna, Austria) and its concentration was determined from its absorption at $430 \mathrm{~nm}\left(\varepsilon_{430}=89,000 \mathrm{M}^{-1} \mathrm{~cm}^{-1}\right)$. Hydrogen peroxide was prepared by diluting a $30 \%$ stock solution and calculating its concentration from its absorption at $240 \mathrm{~nm}$ $\left(\varepsilon_{240}=43.6 \mathrm{M}^{-1} \mathrm{~cm}^{-1}\right)$. All reagents used for buffers and mobile phases were of analytical grade. Stock solutions of the tested compounds were prepared in DMSO for cellular studies or in ethanol for electrochemical and DPPH scavenging assays. For the antioxidant assays, the DMSO stock solutions were diluted in $10 \mathrm{mM}$ phosphate buffered saline pH 7.4 (PBS) generating working solutions of lower concentrations. Ultrapure Milli-Q water from Millipore (Belford, MA, USA) was used for the preparation of buffers and solutions. PMA stock solutions were prepared in DMSO at a concentration of $50.0 \mu \mathrm{M}$ and were diluted to $0.5 \mu \mathrm{M}$ in PBS at the time of use. TMB solution was prepared by dissolving $14 \mathrm{mM}$ TMB and $100 \mu \mathrm{M}$ potassium iodide in $50 \%$ dimethylformamide and $50 \%$ acetic acid $(800 \mathrm{mM})(\mathrm{v} / \mathrm{v})$. A working suspension of human serum opsonised zymosan was prepared as previously described at a final concentration of $10 \mathrm{mg} / \mathrm{mL}$ [19].

2.2. Hydrophobicity Index. The molecular hydrophobicities of caffeic acid and its derivatives were calculated based on their $\log P$ values (partitioning coefficient in noctanol/water) based on Crippen's fragmentation method and were performed using ChemDraw software (ChemDraw Ultra 7.0.1, CambridgeSoft) [20].

2.3. Cyclic Voltammetry. Voltammetric studies were performed and the oxidation potentials, measured as anodic peak potential $\left(E_{\mathrm{pa}}\right)$, were obtained using an Autolab PGSTAT 30 potentiostat/galvanostat (Eco-Chemie, Utrecht, Netherlands). Voltammetric curves were recorded at room temperature using a 3-electrode setup cell. The working electrode was a glassy carbon disk electrode (GC electrode, $3 \mathrm{~mm}$ diameter). The counter electrode was a platinum plate and the reference was an $\mathrm{Ag} / \mathrm{AgCl}$ saturated $\mathrm{KCl}$ at $3 \mathrm{M}$ electrode. The working electrode surface was carefully polished with $0.5 \mu \mathrm{m}$ alumina slurries before each experiment and was thoroughly rinsed with distilled water. A solution of sodium phosphate buffer $0.2 \mathrm{M}(\mathrm{pH}=7)$ was used as a supporting electrolyte. The solutions were purged with nitrogen for $5 \mathrm{~min}$ before recording the voltammograms. The ethanolic solutions $(5 \mathrm{mM})$ of the compounds were diluted in the electrochemical cell at final concentrations of $0.1 \mathrm{mM}$ using the supporting electrolyte solution. The cyclic voltammograms were recorded at a potential scan rate of $5 \mathrm{mV} \mathrm{s}^{-1}[21]$.

2.4. DPPH Scavenging Assay. Caffeic acid and its derivatives were incubated for $30 \mathrm{~min}$ with $100 \mu \mathrm{M}$ DPPH in ethyl alcohol in the dark. The scavenging activity was evaluated spectrophotometrically at $517 \mathrm{~nm}$ using the absorbance of unreacted DPPH radical as a control and was calculated as [(Absorbance of control - absorbance of sample) $/($ absorbance of control)] $\times 100[22]$.

2.5. Triene Degradation Assay. These studies were performed as previously described with modifications [23]. An emulsion 
was prepared by mixing $2.5 \mathrm{mg}$ of tung oil (not stripped of tocopherols) in $25 \mathrm{~mL}$ of PBS containing $17 \mu \mathrm{M}$ Brij 35. The solution was vigorously vortexed to produce a homogeneous emulsion. The assays were performed as follows: the tung oil suspension $(50 \mu \mathrm{L})$ was incubated with freshly prepared $1 \mathrm{mM}$ AAPH (source of peroxyl radical) in $\mathrm{PBS}$ at $37^{\circ} \mathrm{C}$ in the absence (control) or presence of the tested compounds in the wells of a microplate for 3 hours. The final reaction volume was $200 \mu \mathrm{L}$. The microplate was read at $5 \mathrm{~min}$ intervals with shaking for 5 seconds before the measurements were taken. The absorbances were measured at $273 \mathrm{~nm}$ using a Synergy 2 Multimode microplate reader (BioTek, Winooski, VT, USA). The degradation of the eleostearic acid (conjugated triene) produced the absorbance versus time curve for which the area under the curve (AUC) was calculated. Curves of $\left(\mathrm{AUC}_{\text {sample }}-\mathrm{AUC}_{\text {control }}\right)$ against the concentration of each test compound were plotted and their slopes were used as analytical parameters. Trolox was used as a reference antioxidant. The ratio (slope sample $/$ slope $_{\text {trolox }}$ ), which is known as trolox equivalent antioxidant activity (TEAC), was used to assess the relative antioxidant efficacy of the test compounds.

2.6. Reactivity with Hydrogen Peroxide. The reactivity of caffeic acid and its derivatives with $\mathrm{H}_{2} \mathrm{O}_{2}$ was monitored amperometrically with a $\mathrm{H}_{2} \mathrm{O}_{2}$-selective electrode coupled to a Free Radical Analyzer (TRB 4100, World Precision Instruments, USA). The reaction mixtures $(3 \mathrm{~mL})$ were composed of $10 \mathrm{nM} \mathrm{HRP}, 250 \mu \mathrm{M} \mathrm{H}_{2} \mathrm{O}_{2}$, and $250 \mu \mathrm{M}$ of the tested compounds in $0.1 \mathrm{M}$ phosphate buffer, $\mathrm{pH} 7.4$, at $25^{\circ} \mathrm{C}$. The reactions were triggered by adding HRP [24].

2.7. Isolation of Human Leukocytes. Blood samples were obtained from healthy volunteers using heparin as an anticoagulant. Polymorphonuclear neutrophil (PMN) and peripheral blood mononuclear cells (PBMC) were isolated by centrifugation on a Histopaque-1077/1119 gradient at $700 \times \mathrm{g}$ for $30 \mathrm{~min}$ at room temperature [25]. After isolation, the cells were resuspended in PBS supplemented with $1 \mathrm{mM}$ calcium chloride, $0.5 \mathrm{mM}$ magnesium chloride, and $1 \mathrm{mg} / \mathrm{mL}$ glucose (supplemented PBS). Experiments were performed in accordance with regulations of the Research Ethics Committee (21496413.8.0000.5426), Faculty of Pharmaceutical Sciences, Unesp, São Paulo, Brazil.

2.8. Superoxide Anion Production by Activated Leukocytes (Lucigenin-Dependent Chemiluminescence Assay). PMN and PBMC $\left(1 \times 10^{6}\right.$ cells $\left./ \mathrm{mL}\right)$ were preincubated at $37^{\circ} \mathrm{C}$ in supplemented PBS with the test compound for $10 \mathrm{~min}$. Next, lucigenin $(10 \mu \mathrm{M})$ and PMA $(100 \mathrm{nM})$ or opsonised zymosan $(1 \mathrm{mg} / \mathrm{mL})$ were added and the light emission was measured for $30 \mathrm{~min}$ at $37^{\circ} \mathrm{C}$ using a plate luminometer (Centro Microplate Luminometer LB960, Berthold Technologies, Oak Ridge, TN, USA). The final assay volume was $250 \mu \mathrm{L}$. The integrated light emission was used as an analytical parameter to measure the superoxide anion produced by the stimulated cells. The inhibitory potency was calculated using the light emission generated by the control, in which activated cells were incubated in the absence of the test compounds as [26].
2.9. Superoxide Anion Production by Activated Neutrophils (WST-1 Assay). These studies were performed as previously described with modifications [27]. PMN $\left(1.0 \times 10^{6}\right.$ cells $\left./ \mathrm{mL}\right)$ were preincubated at $37^{\circ} \mathrm{C}$ in supplemented PBS with the test compounds for $10 \mathrm{~min}$. Next, WST- $1(500 \mu \mathrm{M})$ and PMA $(100 \mathrm{nM})$ were added and the extracellular release of $\mathrm{O}_{2}{ }^{--}$ was measured by the reduction of WST-1, monitoring the absorbance increase at $450 \mathrm{~nm}$ for $30 \mathrm{~min}$ at $37^{\circ} \mathrm{C}$; this was performed using Synergy 2 Multimode microplate reader (BioTek, Winooski, VT, USA). The inhibitory potency was calculated using the absorbance of the control, in which the PMA-activated cells were incubated in the absence of the test compounds as a reference.

2.10. Superoxide Anion Production by Xanthine/Xanthine Oxidase (WST-1 Assay). The test compounds were incubated at $37^{\circ} \mathrm{C}$ in PBS supplemented with $500 \mu \mathrm{M}$ WST- 1 and $100 \mu \mathrm{M}$ xanthine. The reactions were initiated by the addition of 0.05 unit $/ \mathrm{mL}$ xanthine oxidase and the reduction of WST-1 was assessed by monitoring the absorbance increase at $450 \mathrm{~nm}$ for $15 \mathrm{~min}$ at $37^{\circ} \mathrm{C}$ using Synergy 2 Multimode microplate reader (BioTek, Winooski, VT, USA).

2.11. Production of Hydrogen Peroxide by Activated Neutrophils. The analysis of the production of $\mathrm{H}_{2} \mathrm{O}_{2}$ and release into the extracellular medium was evaluated using the fluorescent probe Amplex Red, as previously described with modifications [28]. PMNs $\left(5 \times 10^{5}\right.$ cells $\left./ \mathrm{mL}\right)$ were preincubated at $37^{\circ} \mathrm{C}$ in supplemented PBS with the test compounds for $10 \mathrm{~min}$. Next, Amplex Red $(500 \mu \mathrm{M})$ and PMA $(100 \mathrm{nM})$ were added and the extracellular release of $\mathrm{H}_{2} \mathrm{O}_{2}$ was measured fluorimetrically at $530 / 590 \mathrm{~nm}$ for $30 \mathrm{~min}$ at $37^{\circ} \mathrm{C}$ using a Synergy 2 Multimode microplate reader (BioTek, Winooski, VT, USA). The inhibitory potency was calculated using the absorbance of the control, in which the PMA-activated cells were incubated in the absence of the tested compounds as a reference.

2.12. Production of Hypochlorous Acid by Activated Neutrophils and by $\mathrm{H}_{2} \mathrm{O}_{2} / M P O$. These studies were performed as described previously with modifications [29]. The neutrophils $\left(1.0 \times 10^{6}\right.$ cells $\left./ \mathrm{mL}\right)$ were preincubated at $37^{\circ} \mathrm{C}$ for $10 \mathrm{~min}$ in supplemented PBS containing $10 \mathrm{mM}$ taurine and the test compounds. The cells were stimulated by the addition of PMA $(100 \mathrm{nM})$ and were incubated for additional $30 \mathrm{~min}$ at $37^{\circ} \mathrm{C}$. The reactions were stopped by the addition of catalase $(20 \mu \mathrm{g} / \mathrm{mL})$ and were centrifuged at $6000 \mathrm{rpm}$. Then, $200 \mu \mathrm{L}$ was transferred into a 96-well plate and the accumulated taurine chloramine was measured by adding $50 \mu \mathrm{L}$ of $\mathrm{TMB}$ solution. The oxidised TMB was detected spectrophotometrically at $655 \mathrm{~nm}$ using Synergy 2 Multimode microplate reader (BioTek, Winooski, VT, USA). The amount of $\mathrm{HOCl}$ produced was calculated using a standard curve which was generated using pure $\mathrm{HOCl}$ and was submitted to the same analytical protocol.

For the cell-free experiments, the reactions were performed in a 96-well plate containing PBS, taurine (10 mM), 
<smiles>O=C(O)/C=C/c1ccc(O)c(O)c1</smiles>

(C1)

$$
\log P=1.15
$$<smiles>O=C(O)C1CC(O)(C(=O)O)CC(O)C(O)C1O</smiles><smiles>O=C(/C=C/c1ccc(O)c(O)c1)OCc1ccccc1</smiles>

(C2)

$\log P=3.15$<smiles>O=C(/C=C/c1ccccc1)OCc1ccccc1</smiles>
(C4)

$\log P=3.93$

FIGURE 1: Molecular structures of caffeic acid, its derivatives, and hydrophobicity indexes (log $P$, partition coefficients n-octanol/water). Caffeic acid (C1), caffeic acid phenethyl ester (C2), chlorogenic acid (C3), and phenethyl cinnamate (C4).

pure MPO $(50 \mathrm{nM}), \mathrm{H}_{2} \mathrm{O}_{2}(50 \mu \mathrm{M})$, and various concentrations of the tested compounds. The reactions were triggered by the addition of $\mathrm{H}_{2} \mathrm{O}_{2}$ and were incubated at $37^{\circ} \mathrm{C}$. After $30 \mathrm{~min}$, the reactions were stopped by the addition of catalase $(20 \mu \mathrm{g} / \mathrm{mL})$ and the accumulated taurine chloramine was measured as described above. The chlorination inhibitory potency was calculated using the control, in which the $\mathrm{MPO} / \mathrm{H}_{2} \mathrm{O}_{2}$ was incubated in the absence of the test compounds as a reference.

2.13. Cytokines Production by Activated Peripheral Blood Mononuclear Cells. Peripheral blood mononuclear cells $(1 \times$ $10^{6}$ cells/mL per well) were cultured in RPMI-1640 (Gibco, Life Technologies, Foster City, CA, USA) medium added with fetal bovine serum (FBS) (Sigma, St. Louis, MO, USA) at $37^{\circ} \mathrm{C}$ in an atmosphere of $5 \% \mathrm{CO}_{2}$, overnight. Cells were stimulated with Staphylococcus aureus (10 to 1 microorganism per cell) after 5 hours of incubation with the test compounds. After additional 18 hours of incubation the supernatants were stored at $-80^{\circ} \mathrm{C}$. TNF- $\alpha$ and IL- 10 were quantified by enzymelinked immunosorbent assay (ELISA) using BD OptEIA Human TNF ELISA Set (Cat. no. 555212) and BD OptEIA Human IL-10 ELISA Set (Cat. no. 555157), respectively, according to the manufacturer's instructions.

2.14. Statistical Analysis. Comparisons were performed using one-way ANOVA multiple comparisons among means, with the Turkey's post hoc test. Results were considered statistically significant when $P<0.05$. The results were expressed as mean and SEM.

\section{Results and Discussion}

3.1. Structures and Hydrophobicity Indexes. As already known, the capacity of a substance to cross a lipid barrier may be crucial for its pharmacological effect [30]. Considering that NADPH oxidases are membrane-bound multienzymatic complexes, we hypothesised that, besides the redox properties, the hydrophobicity could also be relevant for the potency of NADPH oxidase inhibitors. This was our motivation for the study and comparison of caffeic acid and its derivatives as inhibitors of the production of oxidants by activated leukocytes. Figure 1 shows the molecular structures and hydrophobicity indexes of caffeic acid (C1) and its derivatives, caffeic acid phenethyl ester (C2), chlorogenic acid (C3), and phenethyl cinnamate (C4). These compounds were selected with the aim of increasing or decreasing the hydrophobicity compared to $\mathrm{C}$, without any alteration in the oxidisable catechol moiety, C2, and C3, respectively, or by keeping the hydrophobicity and altering the oxidisability as in $\mathrm{C} 4$. From the partitioning coefficient n-octanol/water values depicted in Figure 1, it can be concluded that this goal was reached.

3.2. Oxidation Peak Potential. Most of the substances that have been proposed as inhibitors of NADPH oxidase are redox active compounds, for example, the potent, but nonselective, and toxic diphenyleneiodonium [31]. This compound has a mechanism of action based on the generation of a transient radical and this inhibition occurs after direct phenylation of the redox active flavin prosthetic group of gp91phox, or of adjacent amino acid groups in the enzyme complex [31]. Another example is apocynin, which despite the same controversies about potency and selectivity, is the most commonly used NADPH oxidase inhibitor. For this molecule, the proposed mechanism of action is also dependent on its activation through MPOmediated oxidation [6]. For this reason, prior to the cellbased studies, we measured and compared the oxidation potential of the tested compounds. Here, the oxidation peak potentials, which were measured as anodic peak potentials $\left(E_{\mathrm{pa}}\right)$, were investigated by cyclic voltammetry using a glassy carbon working electrode. The cyclic voltammograms of the compounds obtained at $\mathrm{pH} 7.0$ showed a well-defined anodic wave peaking in the range 0.24 to $0.42 \mathrm{~V}$ (Figure 2). It can also be observed that the esterification provoked only a small 

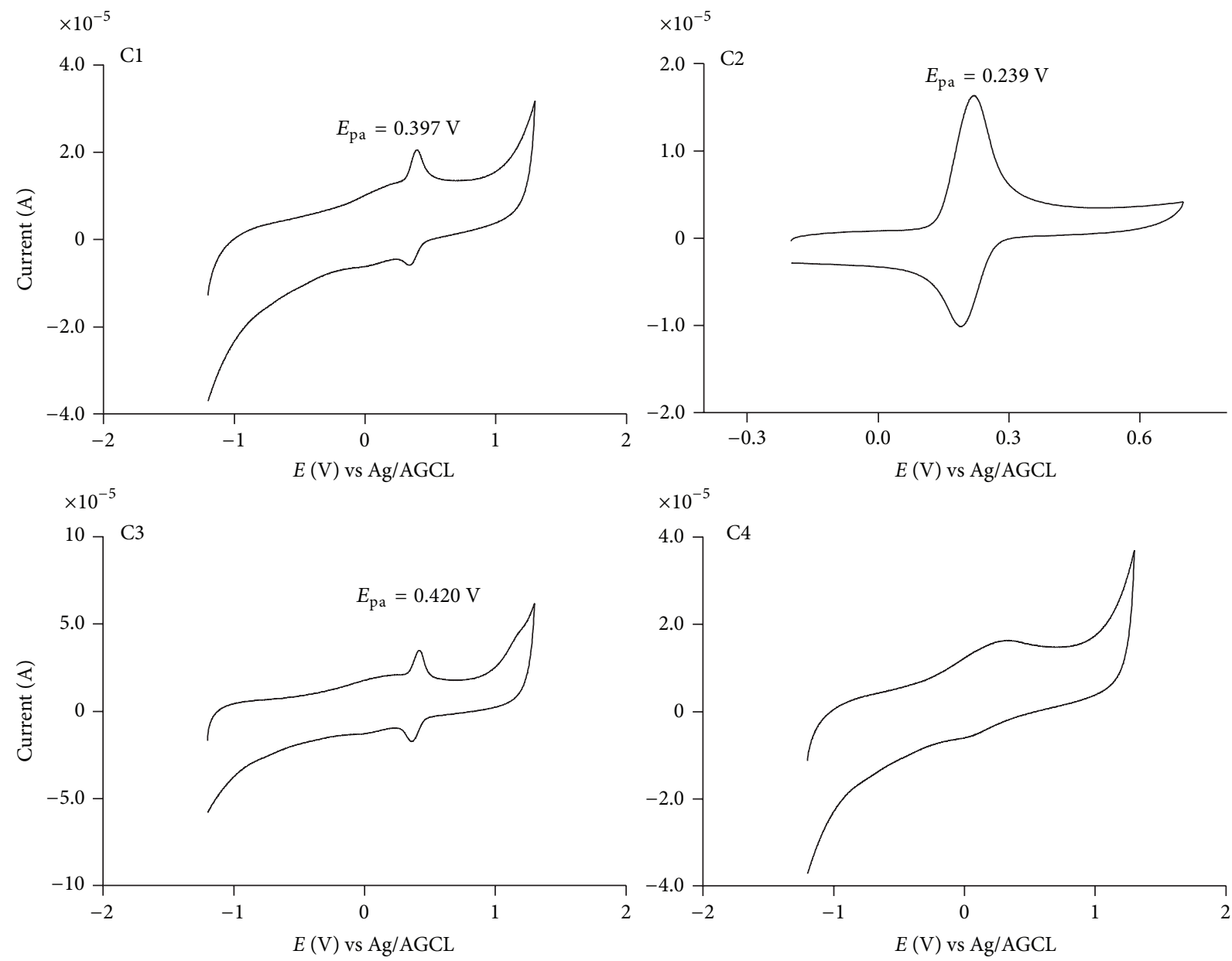

FIGURE 2: Cyclic voltammograms for caffeic acid and its derivatives $(0.1 \mathrm{mM})$ obtained in $0.2 \mathrm{M}$ sodium phosphate buffer at $\mathrm{pH}$ 7.0. The anodic peak potential $\left(E_{\mathrm{pa}}\right)$ is indicated. The scan rate was $5 \mathrm{Mv} \cdot \mathrm{s}^{-1}$.

alteration in the oxidation peak potential, which was not unexpected, since esterification of carboxylic moiety does not provoke significant alterations in the oxidisability of these compounds. For instance, a comparison can be made with other phenolic acids, such as gallic acid $\left(E_{1 / 2} 0.52 \mathrm{~V}\right)$ versus butyl gallate $\left(E_{1 / 2} 0.51 \mathrm{~V}\right)$ [32] or protocatechuic acid $\left(E_{\mathrm{pa}}\right.$ $0.222 \mathrm{~V})$ versus heptyl protocatechuates $\left(E_{\mathrm{pa}} 0.266 \mathrm{~V}\right)$ [18]. For the compounds studied here, the exception was $\mathrm{C} 4$, which did not show a defined anodic wave in the applied voltage range. Obviously, this is a consequence of the absence of a phenolic moiety, making it a redox inactive compound.

3.3. Antioxidant Activity (Cell-Free Assays). The cellular activation of the NADPH oxidase multienzymatic complex results in the generation of ROS; this phenomenon is usually monitored by the use of oxidisable luminescent, chromogenic, and fluorescent probes [33]. Hence, considering the importance of discrimination between the inhibition of the NADPH oxidase enzymatic activity and the simple and direct scavenging of ROS produced by the cells, we performed a complete panel of cell-free assays aiming to study the effects provoked by hydrophobicity on the antioxidant capacity of the test compounds.

Firstly, the compounds were studied by their efficacy as a reducing agent of the stable free radical DPPH. This assay is based on the reduction of this free radical, which is monitored by a decrease in the absorbance; the effective concentration (EC50) value expresses the concentration that is necessary to decrease the absorbance of DPPH by $50 \%$. The EC50 values obtained were $15.7 \pm 0.1,16.4 \pm 0.3$, and $14.1 \pm 0.1 \mu \mathrm{M}$, for $\mathrm{C} 1, \mathrm{C} 2$, and C3, respectively, demonstrating that an alteration in the hydrophobicity did not cause a significant alteration in the reducing capacity of the DPPH free radical. However, as expected due to the absence of the catechol moiety, C4 was totally unable to reduce the DPPH free radical.

In this sequence, the compounds were tested as inhibitors of the $\mathrm{ROO}^{\circ}$-mediated degradation of the conjugated triene present in eleostearic acid. In this assay the azocompound $\mathrm{AAPH}$ decomposes at $37^{\circ} \mathrm{C}$ in aqueous solutions to generate an alkyl radical $\left(\mathrm{R}^{\circ}\right)$, which, in the presence of molecular oxygen, is converted to the corresponding peroxyl radical $\left(\mathrm{ROO}^{\circ}\right)$. The oxidation of the triene was monitored by the bleaching of absorption at $273 \mathrm{~nm}$. The addition of the tested 


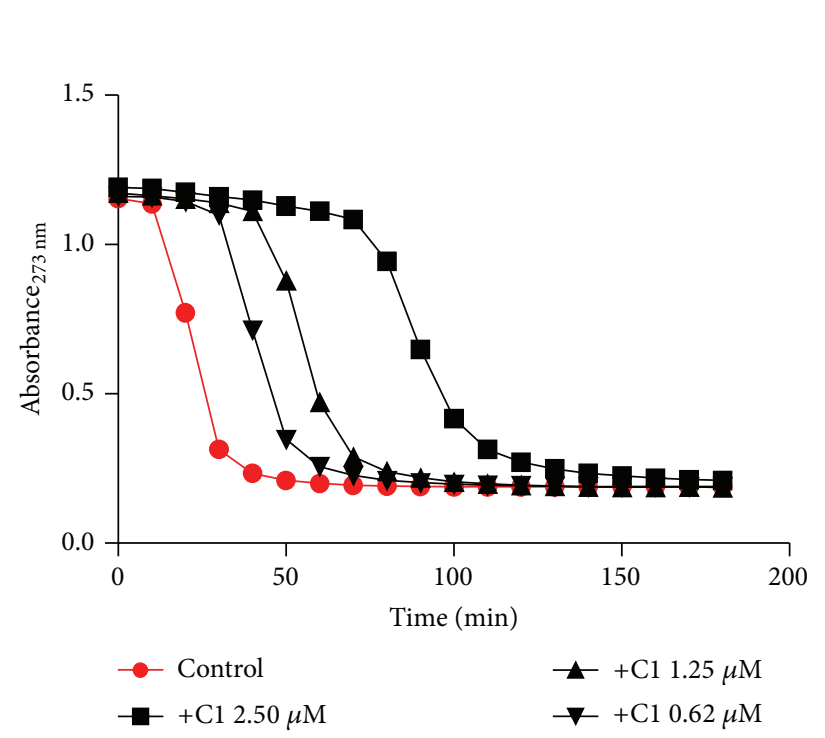

(a)

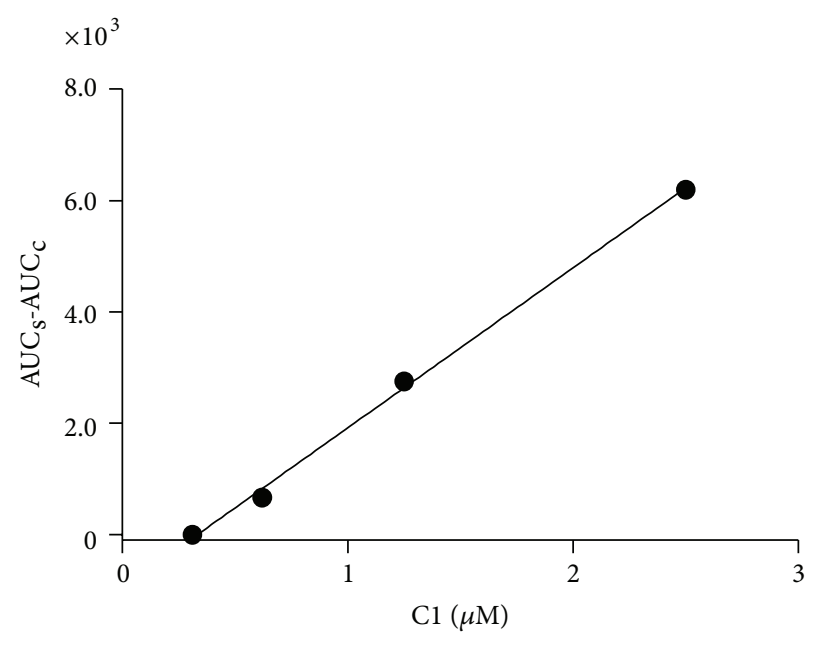

(b)

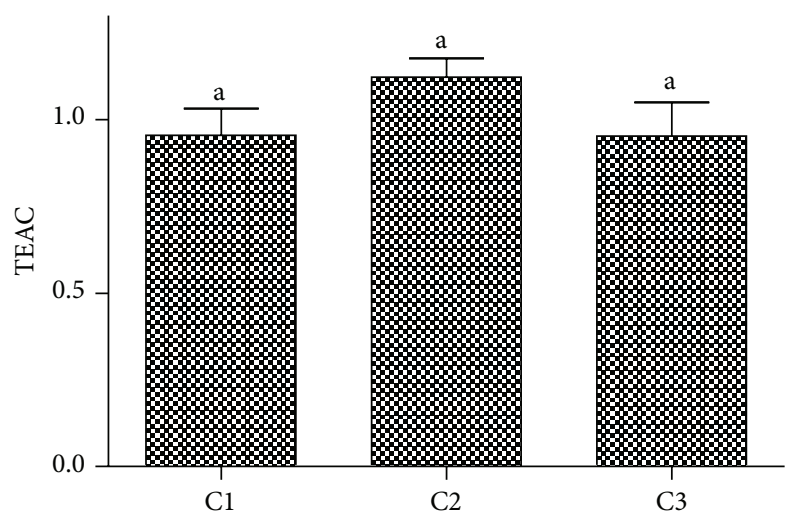

(c)

FIGURE 3: Inhibitory effect of caffeic acid and its derivatives on triene degradation by ROO. (a) Bleaching of triene (eleostearic acid) by ROO and the effect provoked by the addition of C1. (b) Linear relationship between AUC and concentrations of C1. The slopes were calculated from the liner regression curves. (c) Trolox equivalent antioxidant activity (TEAC = slope compound/slope trolox). The results are mean and SEM of triplicate experiments. Different letters denote significant differences. One-way ANOVA and Tukey's multiple comparison test, $P<0.05$.

compounds, by scavenging $\mathrm{ROO}^{\circ}$, delayed the bleaching and produced a concentration-dependent lag phase. The results depicted in Figure 3(a) show the kinetic profile of the fluorescence bleaching and the effect of the addition of $\mathrm{Cl}$ at increasing concentrations. Figure 3(b) shows the relationship between the area under the curve and concentrations of $\mathrm{C} 1$ (similar results were obtained for C2 and C3, not shown). The slope of the linear regression (AUC/concentration) was used as an analytical parameter for assessment of the reactivity of the tested compounds with $\mathrm{ROO}^{\circ}$. The antioxidant trolox, a water soluble derivative of vitamin $\mathrm{E}$, was used for comparison of the antiradical efficacy of the tested compounds. The ratio slope sample $/$ slope $_{\text {trolox }}$ generated the trolox equivalent antioxidant capacity (TEAC) values, which we used to measure the relative antioxidant efficacy of the test compounds. From the results depicted in Figure 3, it can be observed that the tested compounds were as effective as trolox, but no significant difference was obtained between them.

In the next step, caffeic acid and its derivatives were compared regarding their reactivity with $\mathrm{H}_{2} \mathrm{O}_{2}$. In these experiments, the reactions were monitored by amperometry using a $\mathrm{H}_{2} \mathrm{O}_{2}$ selective-electrode. The results displayed in Figure 4 show that the tested compounds were completely nonreactive with $\mathrm{H}_{2} \mathrm{O}_{2}$ in the absence of horseradish peroxidase (HRP). However, the addition of a catalytic amount of HRP caused an instantaneous consumption of $\mathrm{H}_{2} \mathrm{O}_{2}$. No significant difference was obtained between the tested compounds.

3.4. Inhibitory Effect on the Production of Superoxide Anion by Activated Leukocytes. As stated above, $\mathrm{O}_{2}{ }^{--}$is the initial ROS produced by the activation of NADPH oxidase. Hence, this reactive species was our first concern in the cellular 


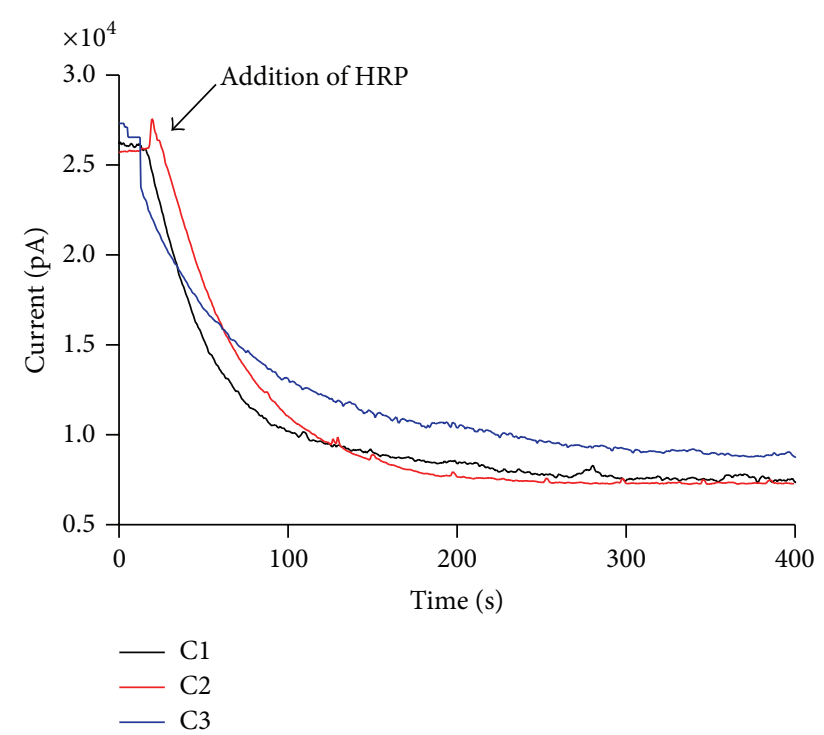

FIGURE 4: Reactivity of the test compounds with hydrogen peroxide. The reaction mixtures were comprised of $0.25 \mathrm{mM}$ of the test compounds, $0.25 \mathrm{mM} \mathrm{H}_{2} \mathrm{O}_{2}$, and $10 \mathrm{nM} \mathrm{HRP}$ in $0.01 \mathrm{M} \mathrm{PBS,} \mathrm{pH} \mathrm{7.4,}$ at $25^{\circ} \mathrm{C}$. The results are representative of three experiments.

assays. For that, caffeic acid and its derivatives were initially studied as inhibitors of lucigenin-dependent chemiluminescence elicited by activated neutrophils. In this reaction, $\mathrm{O}_{2}{ }^{--}$produced by the activation of the NADPH oxidase multienzymatic complex reduces lucigenin to form its cation radical, which reacts with a second $\mathrm{O}_{2}{ }^{--}$to form the energyrich dioxetane molecule that decomposes, emitting light [26].

In contrast to the previous antioxidant assays, $\mathrm{C} 2$ was found to be a significantly more potent inhibitor than the other compounds in this cell-based assay. As can be observed from the results depicted in Figures 5(a) and 5(b), C1 and C4 were totally ineffective, whereas $\mathrm{C} 3$ showed some activity, although this was much lower than that of $\mathrm{C} 2$.

The lucigenin-based assay is widely used for the detection of $\mathrm{O}_{2}{ }^{--}$; however, some controversies have appeared regarding its selectivity for this reactive species [34]. For this reason and considering the higher efficacy of $\mathrm{C} 2$ compared to the other compounds, we also studied the activation of NADPH oxidase in neutrophils using a specific chromogenic probe to $\mathrm{O}_{2}{ }^{-}$. This probe is the sulphonated tetrazolium salt (WST-1), which is similar to nitroblue tetrazolium (NBT), which is a widely used compound for the cytochemical determination of NADPH oxidase in leukocytes by microscopy. Compared to NBT, the advantage of WST-1 is its water solubility and membrane-impermeability. Hence, the formazan salt produced by its specific reaction with $\mathrm{O}_{2}{ }^{\cdot-}$ can be detected in the extracellular medium using conventional absorbance measurements [27]. From the results depicted in Figure 5(c), we can conclude that the higher capacity of $\mathrm{C} 2$ was confirmed using the WST-1 assay. Indeed, the difference between C2 and the other compounds was still higher, which suggests its efficacy as an inhibitor of NADPH oxidase.
To confirm that $\mathrm{C} 2$ was indeed inhibiting the enzymatic activity of NADPH oxidase and not only acting as a scavenger of $\mathrm{O}_{2}{ }^{--}$, an enzymatic and cell-free experiment was performed. For that, we used the xanthine/xanthine oxidase enzymatic system as a source of $\mathrm{O}_{2}{ }^{--}$(Figure 5(d)). As can be seen, using the same concentrations that were used in the cellular experimental model, the direct scavenger effects were minimal and, more importantly, the differences between $\mathrm{C} 1, \mathrm{C} 2$, and C3 were not statistically significant. It is worth noting that the inhibitory effects were not the result of a cytotoxic effect on leukocytes, as confirmed by the trypan blue exclusion assay. At the higher concentration used for the leukocyte studies, the viability of the cells was $>98 \%$ (results not shown).

From the results depicted in Figure 5, it can be seen that apocynin was used as a reference inhibitor [35]. The reason for this choice was, obviously, the large applicability of apocynin as an NADPH oxidase inhibitor. Hence, the higher efficacy of C2 compared to apocynin is an additional indicator of its potential application as an anti-inflammatory compound, as has been widely demonstrated for apocynin.

The inhibitory potency of $\mathrm{C} 2$ was also observed using PBMC instead of neutrophils and again the more lipophilic ester was the more effective one (Figure 6). Our motivation for the use of PBMC relied on the fact that monocytes have a lower content of MPO compared to neutrophils. This is relevant, since MPO may play a role in the mechanism of NADPH oxidase inhibition. This is the case for apocynin, which must be oxidised to perform its role through an MPO-dependent reaction and the consequence is its lower efficacy as an NADPH oxidase inhibitor in PBMC [36]. From the results in Figure 6, it can be seen that the difference between $\mathrm{C} 2$ and apocynin was still higher using PBMC than neutrophils. This is an indication that $\mathrm{C} 2$ is not dependent on MPO for its biological effect.

\subsection{Inhibitory Effect on the Production of Hydrogen Peroxide} by Activated Leukocytes. In the enzymatic cascade for the production and release of oxidants through NADPH oxidase activation, the dismutation of $\mathrm{O}_{2}{ }^{--}$to $\mathrm{H}_{2} \mathrm{O}_{2}$ is the second step [7]. Hence, we also measured and compared the tested compounds as inhibitors of $\mathrm{H}_{2} \mathrm{O}_{2}$ release by activated neutrophils. The measurement of the production of $\mathrm{H}_{2} \mathrm{O}_{2}$ was performed using Ample Red, a specific fluorescent probe for this reactive species, in the extracellular medium [28]. From the data depicted in Figure 7, it can be concluded that $\mathrm{C} 2$ was still the more potent inhibitor. The detection of $\mathrm{H}_{2} \mathrm{O}_{2}$ by Amplex Red is based on its oxidation through a peroxidasecatalysed reaction (MPO in the case of neutrophils). Hence, it is obvious that any redox active compound, such as the phenolic acid derivatives used here, could compete with Amplex Red and provoke an inhibitory effect via the direct scavenging of $\mathrm{H}_{2} \mathrm{O}_{2}$. This fact could explain why, not only C2, as seen in the previous assay, but also $\mathrm{Cl}$ and $\mathrm{C} 3$, provoked an inhibitory effect in the production of $\mathrm{H}_{2} \mathrm{O}_{2}$. These results must be also analysed in light of the previous cell-free based assay for $\mathrm{H}_{2} \mathrm{O}_{2}$, where no difference was obtained between the studied compounds (Figure 4). Hence, the higher efficacy 


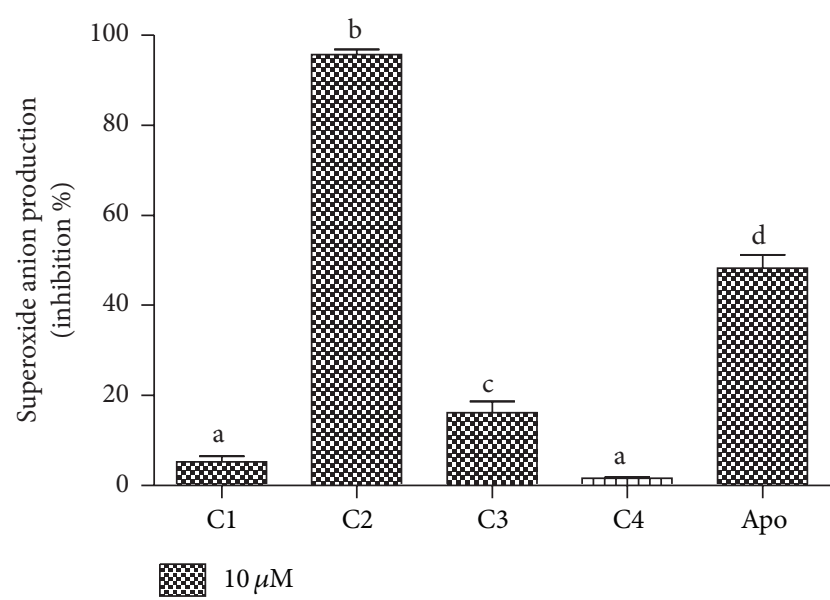

(a)

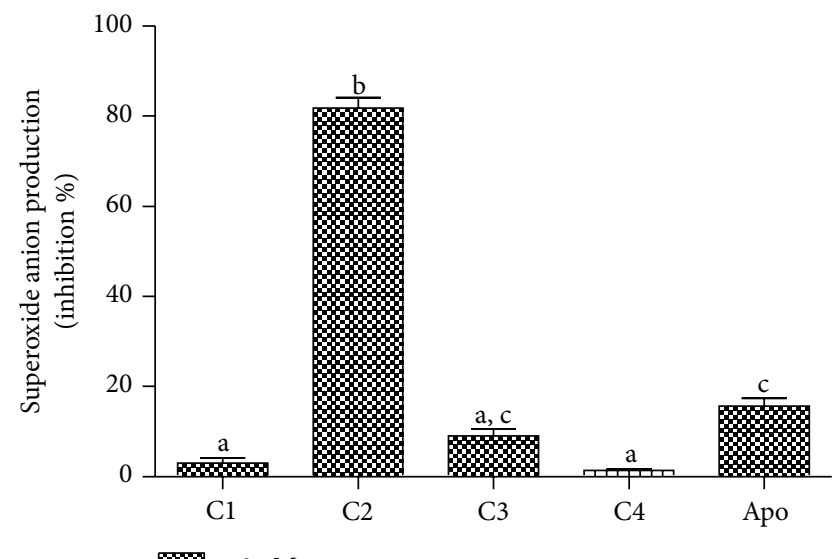

(c)

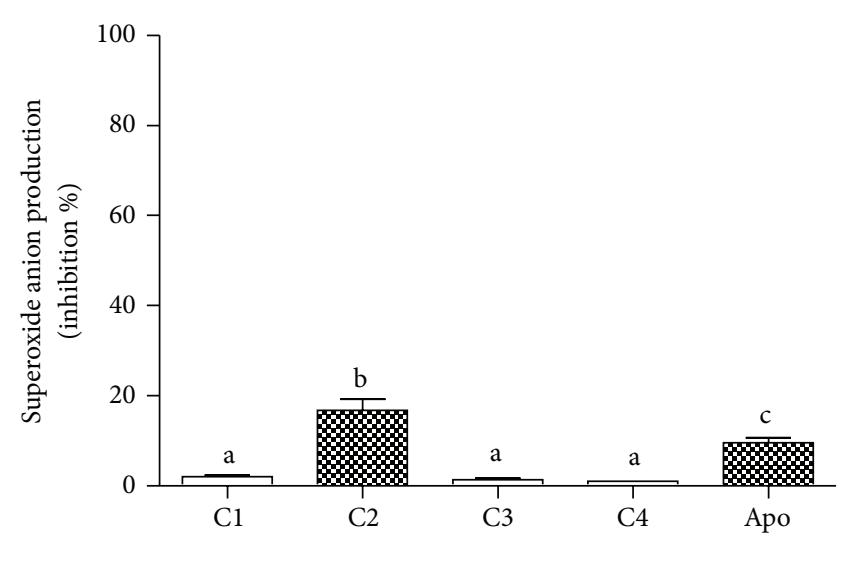

(b)

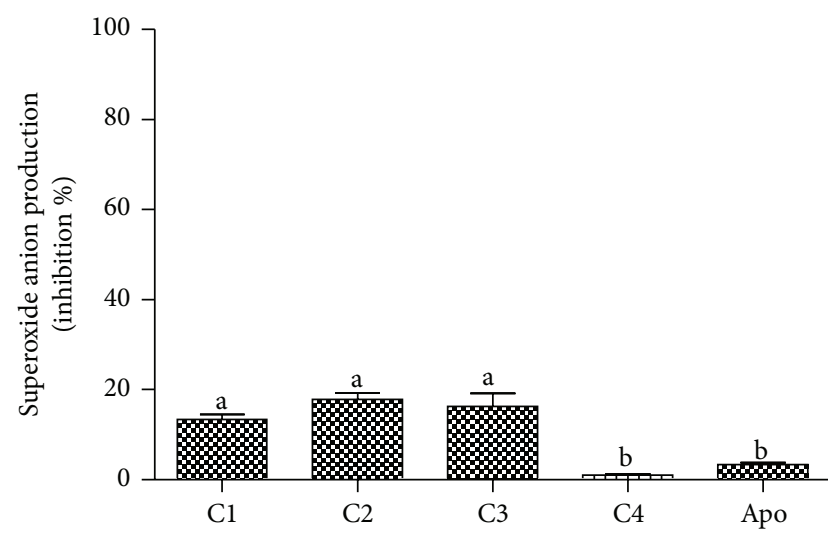

(d)

Figure 5: Caffeic acid, its derivatives, and apocynin (apo) as inhibitors of the production of superoxide anion by stimulated PMN and xanthine/xanthine oxidase. ( $a, b)$ Lucigenin-dependent chemiluminescence elicited by opsonised zymosan-activated PMN. (c) WST-1 reduction elicited by PMA-activated PMN. (d) WST-1 reduction elicited by xanthine/xanthine oxidase. The results are mean and SEM of duplicates of three different experiments. Different letters denote significant differences. One-way ANOVA and Tukey's multiple comparison test, $P<0.05$.

of $\mathrm{C} 2$ in this cell-based assay is one more confirmation of its effect on NADPH oxidase in leukocytes rather than this being a simple scavenging effect.

3.6. Inhibition of the Production of Hypochlorous Acid by Activated Leukocytes. The next step in the enzymatic cascade of reactions that characterises the oxidative burst of neutrophils is the production of $\mathrm{HOCl}$ through the MPOmediated oxidation of chloride using $\mathrm{H}_{2} \mathrm{O}_{2}$ as a cosubstrate. Hence, if $\mathrm{C} 2$ was indeed inhibiting the production of $\mathrm{O}_{2}{ }^{--}$, the production of $\mathrm{HOCl}$ should also be affected. To study this possibility, we used a technique based on trapping the HOCl produced with taurine, which is converted to taurine chloramine. This stable oxidant was detected by the iodidecatalysed oxidation of TMB [37]. From the results depicted in Figure 8(a), it can be noted that, among the phenolic acid derivatives, only $\mathrm{C} 2$ was able to inhibit the production of $\mathrm{HOCl}$.
Three different reasons could explain the decreased production of $\mathrm{HOCl}$ by activated neutrophils in the presence of C2: (i) inhibition of the enzymatic activity of MPO, (ii) direct scavenging of $\mathrm{HOCl}$, and (iii) inhibition of the production of $\mathrm{O}_{2}{ }^{--}$. To discriminate these effects, we measured the capacity of the tested compounds as inhibitors of the chlorinating activity of the purified MPO. From the results depicted in Figure 8(b), we can note that all of the tested compounds, including $\mathrm{C} 2$, were unable to inhibit the formation of $\mathrm{HOCl}$ in the cell-free system. These results also eliminated the direct scavenging effect upon $\mathrm{HOCl}$. Hence, the inhibition of the production of $\mathrm{HOCl}$ without affecting the MPO enzymatic activity is an additional confirmation of the effect of $\mathrm{C} 2$ on NADPH oxidase in neutrophils.

In the $\mathrm{HOCl}$ experiments, we used 5-fluortryptamine as a reference inhibitor. This indole derivative is a potent inhibitor of the chlorinating activity of MPO [38]. In agreement with that, in our hands, 5-fluortryptamine was able to block the 

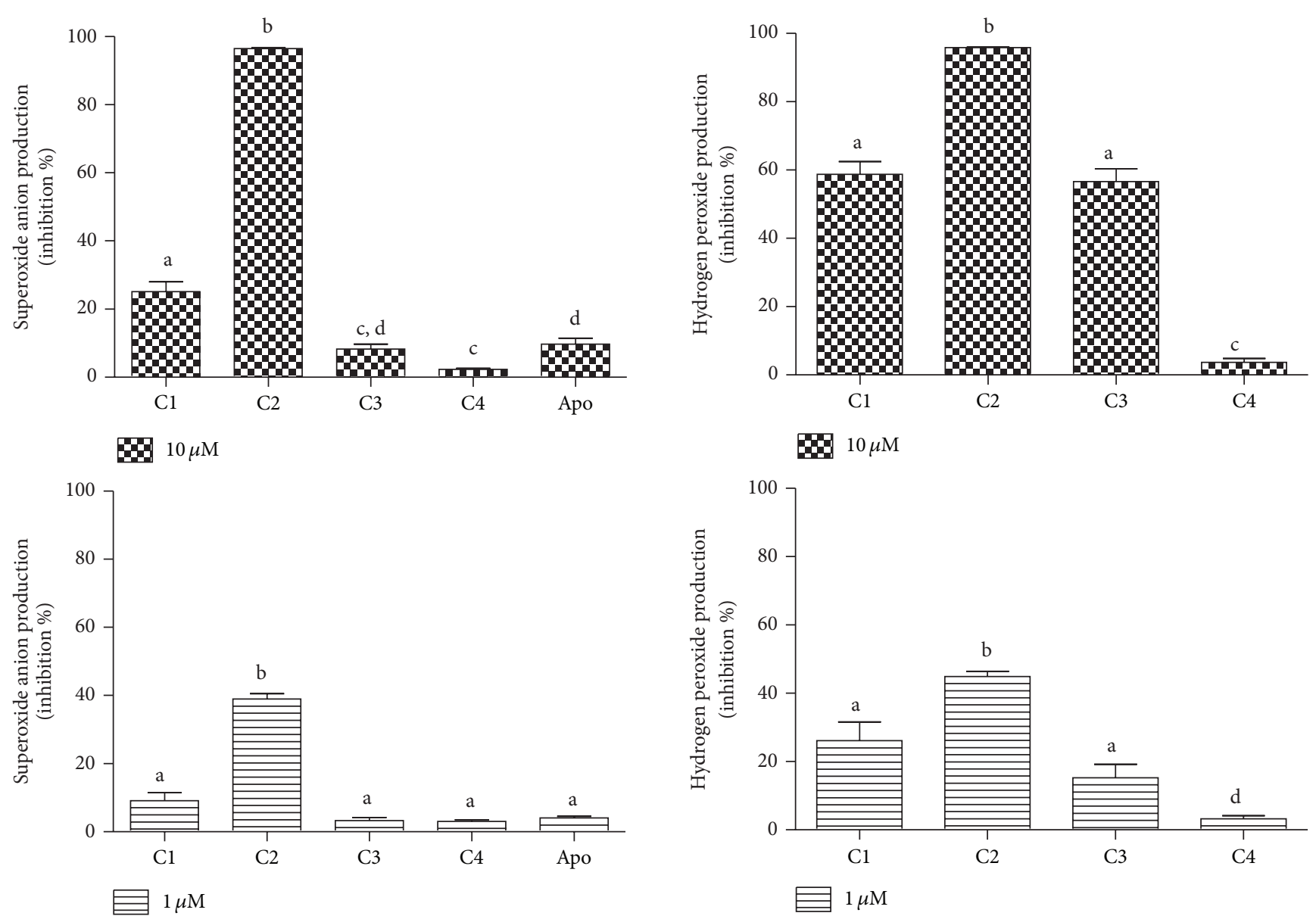

Figure 6: Caffeic acid, its derivatives, and apocynin (apo) as inhibitors of the production of superoxide anion by stimulated PBMC. Lucigenin-dependent chemiluminescence elicited by opsonised zymosan-activated PBMC. The results are mean and SEM of duplicates of three different experiments. Different letters denotes significant difference. One-way ANOVA and Tukey's multiple comparison test $(P<0.05)$.

production of $\mathrm{HOCl}$ in both cell and cell-free assays (Figures $8(\mathrm{a})$ and $8(\mathrm{~b})$ ). However, C2 was only able to exert its effect on neutrophils, which reinforces its specific action upon the NADPH oxidase enzymatic system.

3.7. Inhibition of the Production of TNF- $\alpha$ and IL-10. Tumour necrosis factor- $\alpha$ (TNF- $\alpha$ ) is a major proinflammatory cytokine involved in the inflammatory response. There is evidence of crosstalk between NADPH oxidase and TNF- $\alpha$ in many experimental models using several cell lineages. Some recent findings include the following: the inhibition of NADPH oxidase attenuated TNF- $\alpha$ impaired endothelium-dependent vasodilation [39], increased TNF- $\alpha$ expression associated with diabetes contributes to erectile dysfunction by promoting NAPDH oxidase-mediated ROS generation [40], and TNF- $\alpha$ produces oxidative stress in neuronal cells via the activation of NADPH oxidase through a ceramide-mediated mechanism [41] and so on. Moreover, TNF- $\alpha$ has been shown to prime the neutrophil respiratory

FIgURE 7: Caffeic acid and its derivatives as inhibitors of the production of hydrogen peroxide by stimulated PMN. The results are mean and SEM of duplicates of three different experiments. Different letters denote significant differences. One-way ANOVA and Tukey's multiple comparison test, $P<0.05$.

burst through the partial phosphorylation of p47PHOX [42], which is a cytosolic component of the NADPH oxidase complex.

From the opposite point of view, oxidative stress, which can be initiated by the activation of NADPH oxidase, among other mechanisms, can promote the release of TNF- $\alpha$ through the activation of redox-sensitive transcription factor as nuclear factor-kappa B (NF-kappa B) [43, 44]. Hence, there are numerous demonstrations of the beneficial effect of natural compounds that, besides antioxidative effects, also decrease the production of TNF- $\alpha$ and other proinflammatory cytokines $[10,45,46]$. C2 is included in this class of natural antioxidants that are able to inhibit the release of TNF in many experimental models and using different cell/tissue models $[2,47,48]$. Indeed, C2 was described as a potent and a specific inhibitor of NF-kappa B in the human U937 cell lineage [49].

Considering the relationship between NADPH oxidase and TNF- $\alpha$ production, we also compared $\mathrm{C} 1$ and $\mathrm{C} 2$ as inhibitors of the release of TNF- $\alpha$ by Staphylococcus aureus activated PBMC. From the results depicted in Figure 9, it 


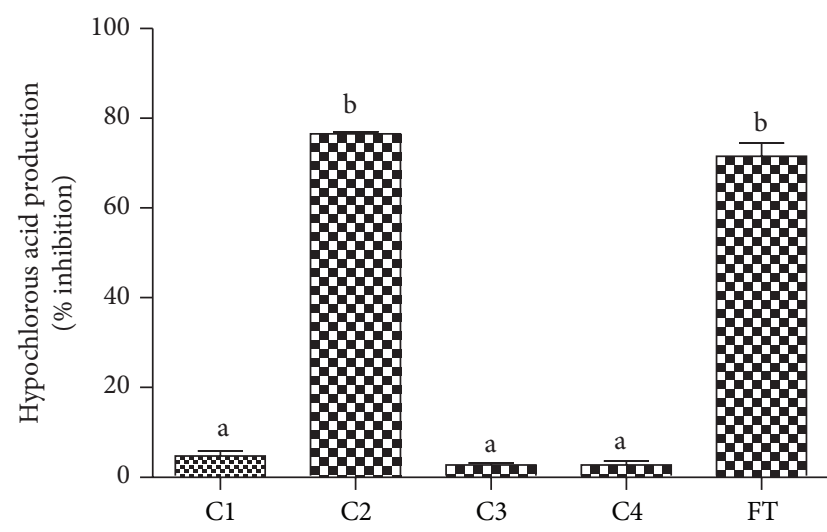

(a)

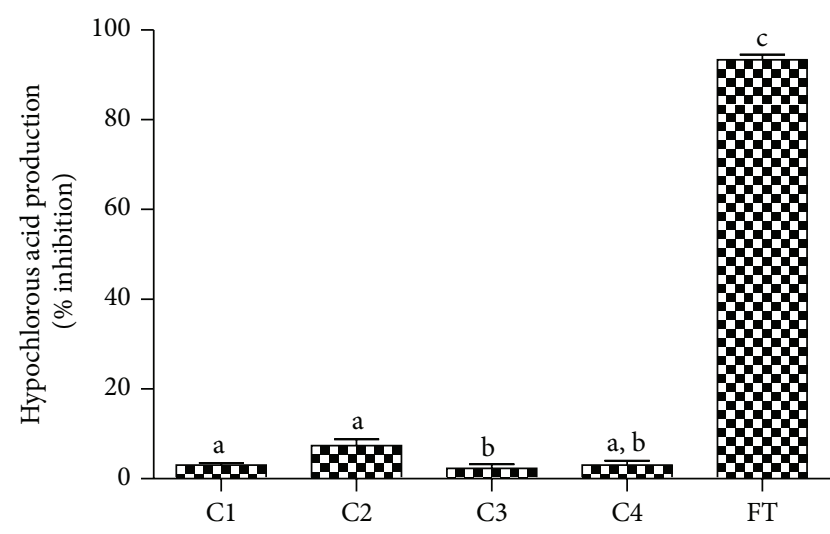

(b)

Figure 8: Caffeic acid, its derivatives, and 5-fluortryptamine (FT) as inhibitors of the production of hypochlorous acid by (a) stimulated PMN and (b) purified MPO. The results are mean and SEM of duplicates of three different experiments. Different letters denote significant differences. One-way ANOVA and Tukey's multiple comparison test, $P<0.05$.

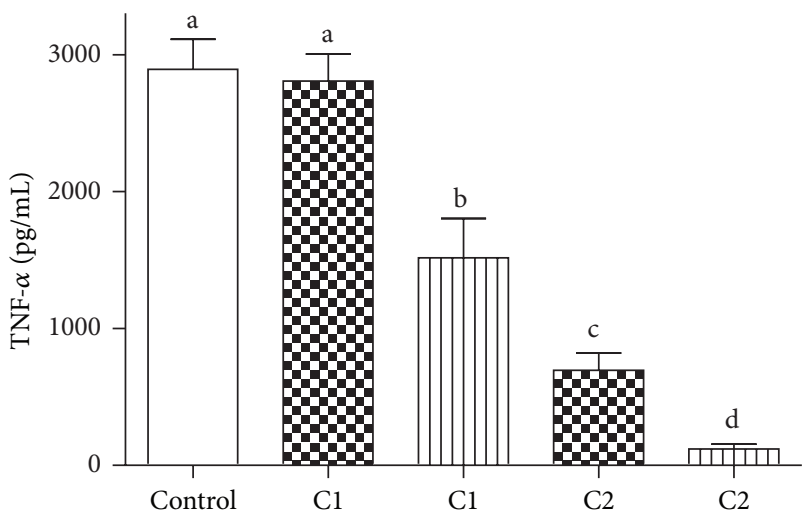

$820 \mu \mathrm{M}$

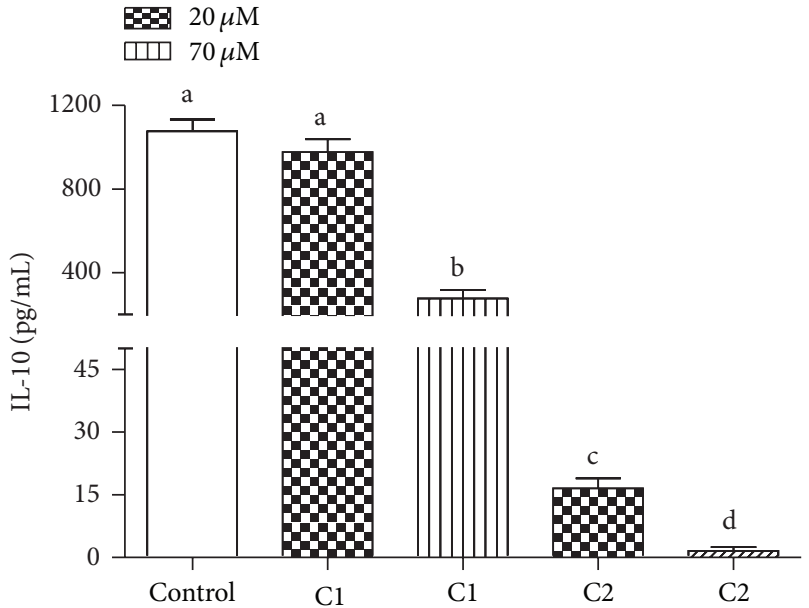

$20 \mu \mathrm{M}$

एाण $70 \mu \mathrm{M}$

can be concluded that the higher hydrophobicity of $\mathrm{C} 2$ was also relevant regarding the inhibition of TNF- $\alpha$. As discussed above, it would be expected that $\mathrm{C} 2$ showed this inhibitory effect, but the finding that it was significantly more effective than $\mathrm{C} 1$, which has similar antioxidant potency, is additional evidence that its hydrophobicity is an important factor in this biological effect, which is closely related to NADPH oxidase activation.

Similar results were obtained for IL-10, an antiinflammatory cytokine whose production by stimulated PBMC is also inhibited by natural antioxidants [50]. Regarding the relationship between NADPH oxidase and IL-10, it has been proposed that this cytokine down regulates the polymorphonuclear neutrophil production of ROS [51]. Hence, similarly to TNF- $\alpha$, our finding that $\mathrm{C} 2$ was also more effective than $\mathrm{C} 1$ as an inhibitor of the production of IL-10 could also be a consequence of the relationship between NADPH oxidase and this cytokine.

\section{Conclusions}

Owing to the involvement of ROS in the pathophysiology of many diseases, several research groups are striving to develop an effective and nontoxic NADPH oxidase inhibitor, which is one of the most important primary sources of superoxide anion in the cells. Here, we have demonstrated, for the first time, that caffeic acid phenethyl ester, besides its extensively described potentially beneficial health properties, is also an effective inhibitor of NADPH oxidase. Our results clearly showed that, besides the redox active catechol moiety, the increased hydrophobicity provoked by the esterification was decisive for this activity. As demonstrated using a panel of assays, the cell-free antioxidant capacity of caffeic acid phenethyl ester was not significantly different from that of the more hydrophilic caffeic acid and chlorogenic acid. On the other hand, in the cell-based assays, caffeic acid phenethyl ester was always the more effective inhibitor. It

FIgUre 9: Production of TNF- $\alpha$ and IL-10 by stimulated PBMC and the inhibitory effect of caffeic acid (C1) and caffeic acid phenethyl ester (C2). The results are mean and SEM of duplicates of six different experiments. Different letters denote significant differences. One-way ANOVA and Tukey's multiple comparison test, $P<0.05$. 
seems clear that these results are a consequence of the capacity of caffeic acid phenethyl ester to diffuse into the cells and to reach the membrane-bound NADPH oxidase multienzymatic complexes.

As a potential NADPH oxidase inhibitor, this propolis component can be used for the treatment of chronic inflammatory diseases; hence, a remaining question is what dosage should be used to reach a pharmacologically efficient plasma concentration. In this context, an analytical method to determine caffeic acid phenethyl ester in rat plasma and urine was developed and the pharmacokinetic studies showed that it is rapidly absorbed and excreted in urine both as an unmodified molecule and as a glucuronide conjugate [52]. In this study, $100 \mathrm{mg} / \mathrm{kg}$ was orally administered, but the recovered caffeic acid phenethyl ester was only 0.007 to $0.021 \%$, which is an indication that it was promptly hydrolysed by plasmatic esterases [52], probably to its caffeic acid precursor. As we have demonstrated here, caffeic acid was significantly less efficient compared to the ester derivative, hence an effective dose of caffeic acid phenethyl ester for in vivo studies could be significantly higher than that obtained in cell-based studies. For this reason, we suggest that the effective concentrations of caffeic acid phenethyl ester found in cell-based studies should be only used as an initial parameter for in vivo applications.

\section{Conflict of Interests}

The authors declare that there is no conflict of interests regarding the publication of this paper.

\section{Acknowledgments}

This work has been partially supported by the Brazilian agency, CAPES, the São Paulo Research Foundation (FAPESP), and the National Council for Scientific and Technological Development (CNPq).

\section{References}

[1] M. L. Khalil, "Biological activity of bee propolis in health and disease," Asian Pacific Journal of Cancer Prevention, vol. 7, no. 1, pp. 22-31, 2006.

[2] C. Gebhard, B. E. Stähli, S. Largiadèr et al., "Caffeic acid phenethyl ester inhibits endothelial tissue factor expression," Biological and Pharmaceutical Bulletin, vol. 36, no. 6, pp. 10321035, 2013.

[3] K. C. Pramanik, S. K. Kudugunti, N. M. Fofaria, M. Y. Moridani, and S. K. Srivastava, "Caffeic acid phenethyl ester suppresses melanoma tumor growth by inhibiting PI3K/AKT/XIAP pathway," Carcinogenesis, vol. 34, no. 9, pp. 2061-2070, 2013.

[4] J. S. dos Santos and A. Monte-Alto-Costa, "Caffeic acid phenethyl ester improves burn healing in rats through antiinflammatory and antioxidant effects," Journal of Burn Care and Research, vol. 34, no. 6, pp. 682-688, 2013.

[5] K. Cui, W. Lu, L. Zhu, X. Shen, and J. Huang, "Caffeic acid phenethyl ester (CAPE), an active component of propolis, inhibits Helicobacter pylori peptide deformylase activity," Biochemical and Biophysical Research Communications, vol. 435, no. 2, pp. 289-294, 2013.
[6] P. Kleniewska, A. Piechota, B. Skibska, and A. Gorąca, "The NADPH oxidase family and its inhibitors," Archivum Immunologiae et Therapiae Experimentalis, vol. 60, no. 4, pp. 277-294, 2012.

[7] D. C. Dale, L. Boxer, and W. Conrad Liles, "The phagocytes: neutrophils and monocytes," Blood, vol. 112, no. 4, pp. 935-945, 2008.

[8] A. Simonyi, Y. He, W. Sheng et al., "Targeting NADPH oxidase and phospholipases A2 in alzheimer's disease," Molecular Neurobiology, vol. 41, no. 2-3, pp. 73-86, 2010.

[9] H. Zhou, F. Zhang, S. Chen et al., "Rotenone activates phagocyte $\mathrm{NADPH}$ oxidase by binding to its membrane subunit gp91 phox," Free Radical Biology and Medicine, vol. 52, no. 2, pp. 303313, 2012.

[10] M. T. Fischer, R. Sharma, J. L. Lim et al., "NADPH oxidase expression in active multiple sclerosis lesions in relation to oxidative tissue damage and mitochondrial injury," Brain, vol. 135, no. 3, pp. 886-899, 2012.

[11] C. Lin and H. Wang, "NADPH oxidase is involved in $\mathrm{H} 2 \mathrm{O} 2$ induced differentiation of human promyelocytic leukaemia HL60 cells," Cell Biology International, vol. 36, no. 4, pp. 391-395, 2012.

[12] I. Takac, K. Schröder, and R. P. Brandes, "The nox family of NADPH Oxidases: friend or foe of the vascular system?" Current Hypertension Reports, vol. 14, no. 1, pp. 70-78, 2012.

[13] G. R. Drummond, S. Selemidis, K. K. Griendling, and C. G. Sobey, "Combating oxidative stress in vascular disease: NADPH oxidases as therapeutic targets," Nature Reviews Drug Discovery, vol. 10, no. 6, pp. 453-471, 2011.

[14] J. Pečivová, T. Mačičková, K. Sviteková, and R. Nosál', "Quercetin inhibits degranulation and superoxide generation in PMA stimulated neutrophils," Interdisciplinary Toxicology, vol. 5, no. 2, pp. 81-83, 2012.

[15] F. Chen, L. Qian, B. Deng, Z. Liu, Y. Zhao, and Y. Le, "Resveratrol protects vascular endothelial cells from high glucose-induced apoptosis through inhibition of nadph oxidase activationdriven oxidative stress," CNS Neuroscience and Therapeutics, vol. 19, no. 9, pp. 675-681, 2013.

[16] M. Ciz, P. Denev, M. Kratchanova, O. Vasicek, G. Ambrozova, and A. Lojek, "Flavonoids inhibit the respiratory burst of neutrophils in mammals," Oxidative Medicine and Cellular Longevity, vol. 2012, Article ID 181295, 6 pages, 2012.

[17] I. H. Philippens, J. A. Wubben, B. Finsen, and B. A. 'T Hart, "Oral treatment with the NADPH oxidase antagonist apocynin mitigates clinical and pathological features of parkinsonism in the MPTP marmoset model," Journal of Neuroimmune Pharmacology, vol. 8, no. 3, pp. 715-726, 2013.

[18] C. M. Q. G. de Faria, A. C. Nazaré, M. S. Petrônio et al., "Protocatechuic acid alkyl esters: hydrophobicity as a determinant factor for inhibition of NADPH oxidase," Current Medicinal Chemistry, vol. 19, no. 28, pp. 4885-4893, 2012.

[19] A. Lojek, L. Kubala, H. Čížová, and M. Č́íž, “A comparison of whole blood neutrophil chemiluminescence measured with cuvette and microtitre plate luminometers," Luminescence, vol. 17, no. 1, pp. 1-4, 2002.

[20] A. K. Ghose and G. M. Crippen, "Atomic physicochemical parameters for three-dimensional-structure-directed quantitative structure-activity relationships. 2. Modeling dispersive and hydrophobic interactions," Journal of Chemical Information and Computer Science®, vol. 27, pp. 21-35, 1987.

[21] M. L. Zeraik, V. F. Ximenes, L. O. Regasini et al., " 4 ' aminochalcones as novel inhibitors of the chlorinating activity 
of myeloperoxidase," Current Medicinal Chemistry, vol. 19, no. 31, pp. 5405-5413, 2012.

[22] W. Brand-Williams, M. E. Cuvelier, and C. Berset, "Use of a free radical method to evaluate antioxidant activity," LWT-Food Science and Technology, vol. 28, no. 1, pp. 25-30, 1995.

[23] M. Laguerre, L. J. López-Giraldo, J. Lecomte et al., "Conjugated autoxidizable triene (CAT) assay: a novel spectrophotometric method for determination of antioxidant capacity using triacylglycerol as ultraviolet probe," Analytical Biochemistry, vol. 380, no. 2, pp. 282-290, 2008.

[24] M. S. Petrônio, M. L. Zeraik, L. M. da Fonseca, and V. F. Ximenes, "Apocynin: chemical and biophysical properties of a NADPH oxidase inhibitor," Molecules, vol. 18, no. 3, pp. 28212839, 2013.

[25] D. English and B. R. Andersen, "Single step separation of red blood cells, granulocytes and mononuclear leukocytes on discontinuous density gradients of Ficoll Hypaque," Journal of Immunological Methods, vol. 5, no. 3, pp. 249-252, 1974.

[26] A. C. de Almeida, O. C. Marques, C. Arslanian, A. CondinoNeto, and V. F. Ximenes, "4-fluoro-2-methoxyphenol, an apocynin analog with enhanced inhibitory effect on leukocyte oxidant production and phagocytosis," European Journal of Pharmacology, vol. 660, no. 2-3, pp. 445-453, 2011.

[27] A. S. Tan and M. V. Berridge, "Superoxide produced by activated neutrophils efficiently reduces the tetrazolium salt, WST-1 to produce a soluble formazan: a simple colorimetric assay for measuring respiratory burst activation and for screening antiinflammatory agents," Journal of Immunological Methods, vol. 238, no. 1-2, pp. 59-68, 2000.

[28] M. Zhou, Z. Diwu, N. Panchuk-Voloshina, and R. P. Haugland, "A stable nonfluorescent derivative of resorufin for the fluorometric determination of trace hydrogen peroxide: Applications in detecting the activity of phagocyte NADPH oxidase and other oxidases," Analytical Biochemistry, vol. 253, no. 2, pp. 162$168,1997$.

[29] V. F. Ximenes, I. M. M. Paino, O. M. M. de Faria-Oliveira, L. M. da Fonseca, and I. L. Brunetti, "Indole ring oxidation by activated leukocytes prevents the production of hypochlorous acid," Brazilian Journal of Medical and Biological Research, vol. 38, no. 11, pp. 1575-1583, 2005.

[30] E. Rutkowska, K. PajIk, and K. Jóźwiak, "Lipophilicitymethods of determination and its role in medicinal chemistry," Acta Poloniae Pharmaceutica, vol. 70, no. 1, pp. 3-18, 2013.

[31] V. B. O’Donnell, D. G. Tew, O. T. G. Jones, and P. J. England, "Studies on the inhibitory mechanism of iodonium compounds with special reference to neutrophil NADPH oxidase," Biochemical Journal, vol. 290, no. 1, pp. 41-49, 1993.

[32] S. Gunckel, P. Santander, G. Cordano et al., "Antioxidant activity of gallates: an electrochemical study in aqueous media," Chemico-Biological Interactions, vol. 114, no. 1-2, pp. 45-59, 1998.

[33] C. C. Winterbourn, "The challenges of using fluorescent probes to detect and quantify specific reactive oxygen species in living cells," Biochimica et Biophysica Acta, vol. 1840, no. 2, pp. 730738, 2014.

[34] M. Barbacanne, J. Souchard, B. Darblade et al., "Detection of superoxide anion released extracellularly by endothelial cells using cytochrome c reduction, ESR, fluorescence and lucigeninenhanced chemiluminescence techniques," Free Radical Biology and Medicine, vol. 29, no. 5, pp. 388-396, 2000.

[35] J. Stefanska and R. Pawliczak, "Apocynin: molecular aptitudes," Mediators of Inflammation, vol. 2008, Article ID 106507, 10 pages, 2008.
[36] A. C. de Almeida, M. M. dos Santos Vilela, A. Condino-Neto, and V. F. Ximenes, "The importance of myeloperoxidase in apocynin-mediated NADPH oxidase inhibition," ISRN Inflammation, vol. 2012, Article ID 260453, 7 pages, 2012.

[37] A. J. Kettle, A. M. Albrett, A. L. Chapman et al., "Measuring chlorine bleach in biology and medicine," Biochimica et Biophysica Acta, vol. 1840, no. 2, pp. 781-793, 2013.

[38] A. C. de Almeida, O. C. Marques, C. Arslanian, A. CondinoNeto, and V. F. Ximenes, "4-Fluoro-2-methoxyphenol, an apocynin analog with enhanced inhibitory effect on leukocyte oxidant production and phagocytosis," European Journal of Pharmacology, vol. 660, no. 2-3, pp. 445-453, 2011.

[39] Y. Huang, L. Yan, S. Rong, H. Haller, and T. Kirch, "TNF- $\alpha$ induces endothelial dysfunction via PKC- $\zeta$-dependent NADPH oxidase activation," Journal of Huazhong University of Science and Technology. Medical Science, vol. 32, no. 5, pp. 642-647, 2012.

[40] T. Long, G. Liu, Y. Wang, Y. Chen, Y. Zhang, and D. Qin, "TNF- $\alpha$, erectile dysfunction, and NADPH oxidasemediated ROS generation in corpus cavernosum in high-fat diet/ streptozotocin-induced diabetic rats," Journal of Sexual Medicine, vol. 9, no. 7, pp. 1801-1814, 2012.

[41] B. M. Barth, S. J. Gustafson, J. L. Hankins et al., "Ceramide kinase regulates $\mathrm{TNF} \alpha$-stimulated $\mathrm{NADPH}$ oxidase activity and eicosanoid biosynthesis in neuroblastoma cells," Cellular Signalling, vol. 24, no. 6, pp. 1126-1133, 2012.

[42] C. Dewas, P. M. Dang, M. Gougerot-Pocidalo, and J. El-Benna, "TNF- $\alpha$ induces phosphorylation of p47phox in human neutrophils: Partial phosphorylation of $\mathrm{p} 47 \mathrm{phox}$ is a common event of priming of human neutrophils by TNF- $\alpha$ and granulocytemacrophage colony-stimulating factor," Journal of Immunology, vol. 171, no. 8, pp. 4392-4398, 2003.

[43] A. Csiszar, M. Wang, E. G. Lakatta, and Z. Ungvari, "Inflammation and endothelial dysfunction during aging: role of NF- $\kappa \mathrm{B}$," Journal of Applied Physiology, vol. 105, no. 4, pp. 1333-1341, 2008.

[44] A. Muñoz and M. Costa, "Nutritionally mediated oxidative stress and inflammation," Oxidative Medicine and Cellular Longevity, vol. 2013, Article ID 610950, 11 pages, 2013.

[45] M. S. Baliga, N. Joseph, M. V. Venkataranganna, A. Saxena, V. Ponemone, and R. Fayad, "Curcumin, an active component of turmeric in the prevention and treatment of ulcerative colitis: preclinical and clinical observations," Food and Function, vol. 3, no. 11, pp. 1109-1117, 2012.

[46] C. Lin and H. Wang, "NADPH oxidase is involved in $\mathrm{H}_{2} \mathrm{O}_{2}$ induced differentiation of human promyelocytic leukaemia HL60 cells," Cell Biology International, vol. 36, no. 4, pp. 391-395, 2012.

[47] S. Juman, N. Yasui, K. Ikeda et al., "Caffeic acid phenethyl ester suppresses the production of pro-inflammatory cytokines in hypertrophic adipocytes through lipopolysaccharidestimulated macrophages," Biological and Pharmaceutical Bulletin, vol. 35, no. 11, pp. 1941-1946, 2012.

[48] T. Çakır, E. Özkan, E. Dulundu et al., "Caffeic acid phenethyl ester (CAPE) prevents methotrexate-induced hepatorenal oxidative injury in rats," The Journal of Pharmacy and Pharmacology, vol. 63, no. 12, pp. 1566-1571, 2011.

[49] K. Natarajan, S. Singh, T. R. Burke Jr., D. Grunberger, and B. B. Aggarwal, "Caffeic acid phenethyl ester is a potent and specific inhibitor of activation of nuclear transcription factor NF- $\kappa \mathrm{B}$," Proceedings of the National Academy of Sciences of the United States of America, vol. 93, no. 17, pp. 9090-9095, 1996. 
[50] P. M. Dang, C. Elbim, J. Marie, M. Chiandotto, M. GougerotPocidalo, and J. El-Benna, "Anti-inflammatory effect of interleukin-10 on human neutrophil respiratory burst involves inhibition of GM-CSF-induced p47PHOX phosphorylation through a decrease in ERK1/2 activity," The FASEB Journal, vol. 20, no. 9, pp. 1504-1506, 2006.

[51] M. Bergman, M. Djaldetti, H. Salman, and H. Bessler, "On the combined effect of statins and lycopene on cytokine production by human peripheral blood cells," Heart and Vessels, vol. 25, no. 5, pp. 426-431, 2010.

[52] N. Celli, B. Mariani, L. K. Dragani, S. Murzilli, C. Rossi, and D. Rotilio, "Development and validation of a liquid chromatographic-tandem mass spectrometric method for the determination of caffeic acid phenethyl ester in rat plasma and urine," Journal of Chromatography B: Analytical Technologies in the Biomedical and Life Sciences, vol. 810, no. 1, pp. 129-136, 2004. 


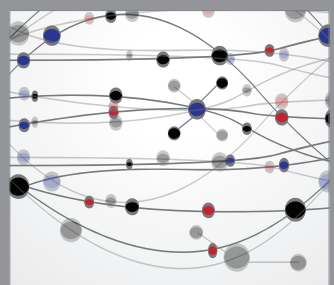

The Scientific World Journal
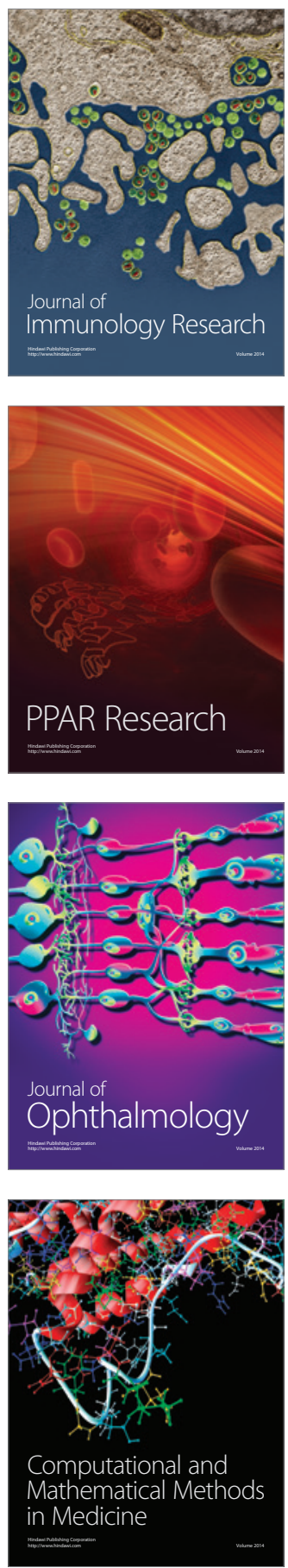

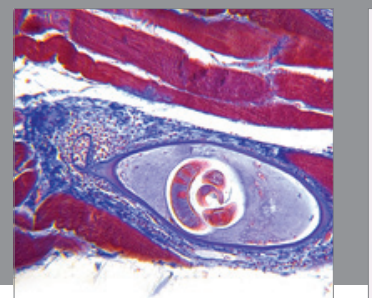

Gastroenterology

Research and Practice
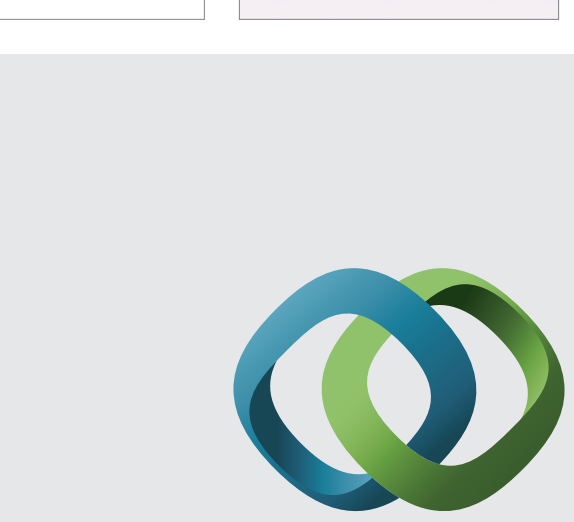

\section{Hindawi}

Submit your manuscripts at

http://www.hindawi.com
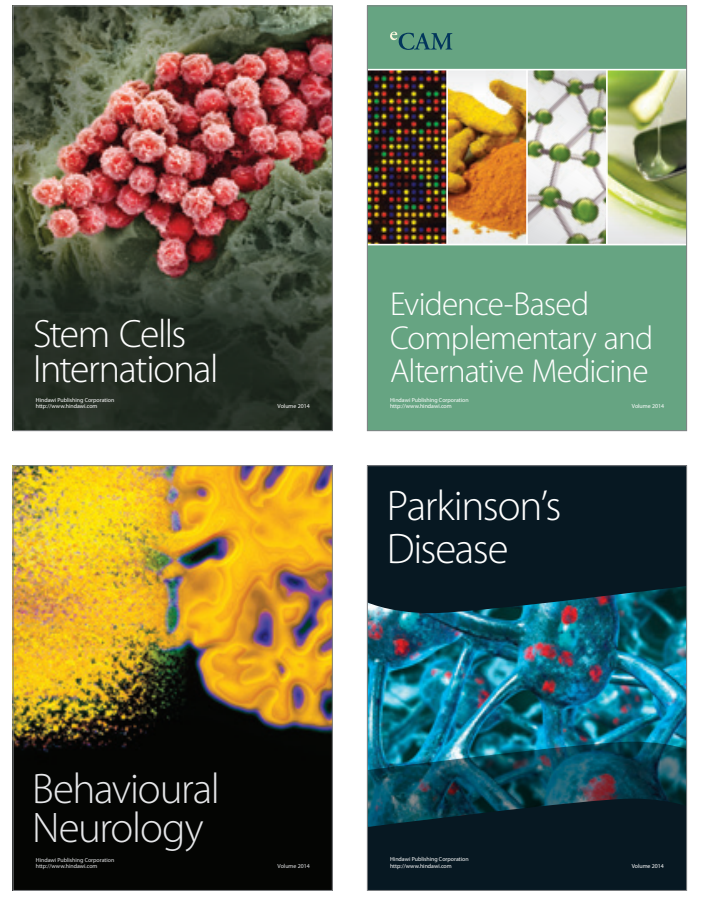
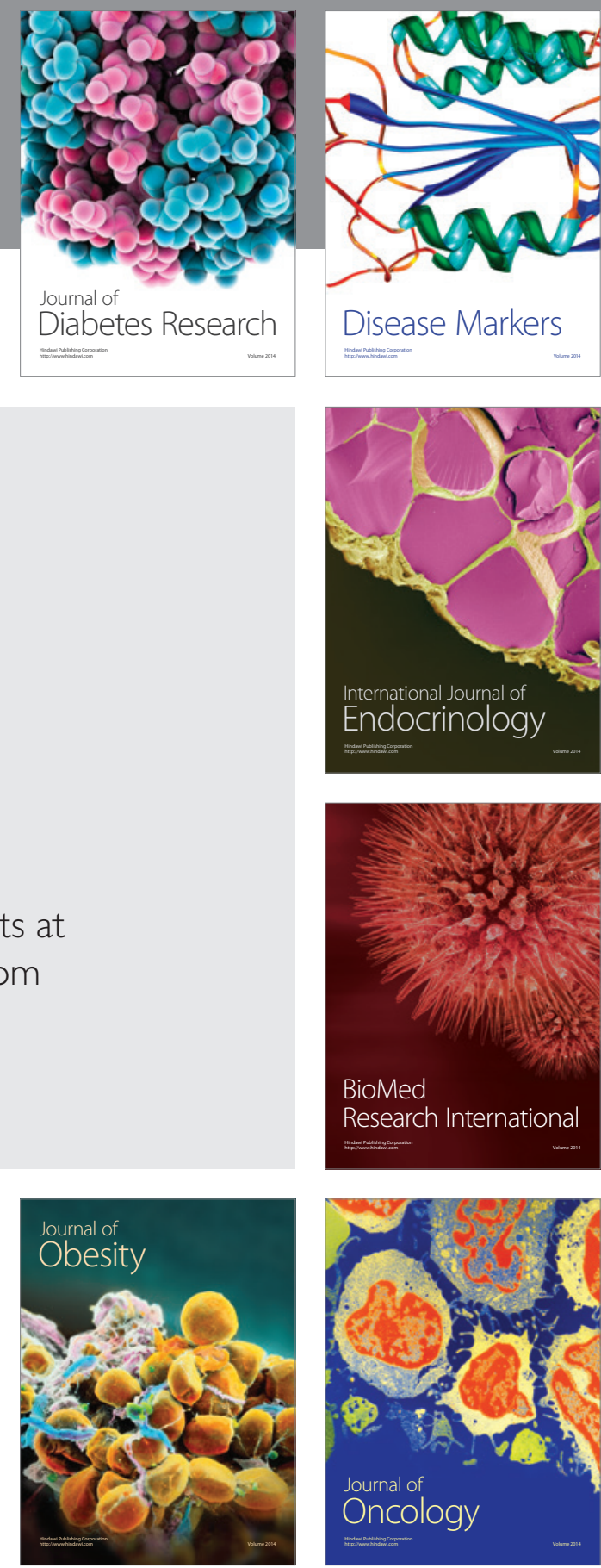

Disease Markers
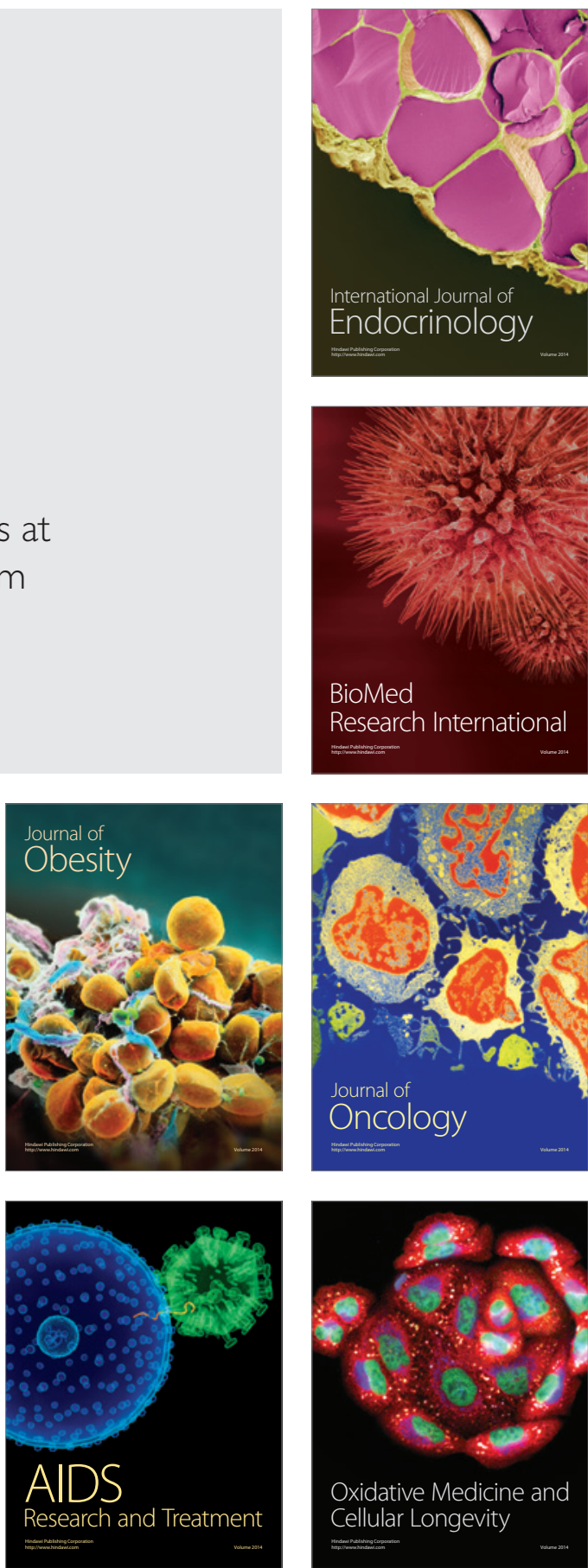